\title{
Nanosized octahedral LiNi0.5Mn1.504 with predominant (111) facet as high performance cathode for Lithium-ion batteries
}

Haibo Rong ( $\nabla 76486366 @ q q . c o m$ )

Foshan University https://orcid.org/0000-0002-4737-6086

Binglu Deng

Foshan University

Dongchu Chen

Foshan University

Min Chen

Foshan University

\section{Research Article}

Keywords: Lithium ion batteries, Cathode, LiNi0.5Mn1.504

Posted Date: September 28th, 2020

DOI: https://doi.org/10.21203/rs.3.rs-81424/v1

License: (a) (i) This work is licensed under a Creative Commons Attribution 4.0 International License. Read Full License 


\section{Abstract}

Nanosized octahedral $\mathrm{LiNi}_{0.5} \mathrm{Mn}_{1.5} \mathrm{O}_{4}$ with predominant (111) facet has been successfully fabricated using $\mathrm{Mn}_{3} \mathrm{O}_{4}$ nanoparticles precursors via a two-step synthesis, which involves a hydrothermal treatment and the subsequent calcination. The physical properties of the $\mathrm{Mn}_{3} \mathrm{O}_{4}$ precursor and the resultant $\mathrm{LiNi}_{0.5} \mathrm{Mn}_{1.5} \mathrm{O}_{4}$ were characterized by XRD (X-ray diffraction), TEM (transmission electron microscopy) and SEM (scanning electron microscopy). The charge-discharge tests show that the resultant $\mathrm{LiNi}_{0.5} \mathrm{Mn}_{1.5} \mathrm{O}_{4}$ exhibits excellent cyclability and rate capability, which delivers a discharge capacity of about $117 \mathrm{mAh} \mathrm{g}^{-1}$ after 300 cycles, and maintains $94 \%$ of its initial discharge capacity (124.7 $\mathrm{mAh} \mathrm{g}^{-1}$ ) at $1 \mathrm{C}$, even at a rate of $40 \mathrm{C}$, a specific capacity of $99.2 \mathrm{mAh} \mathrm{g}^{-1}$ could be still obtained for the O-LNMO. The superior electrochemical performance of the LNMO is mainly attributed to the synergistic effect of the nanosized octahedral structure and exposed (111) facets of the prepared $\mathrm{LiNi}_{0.5} \mathrm{Mn}_{1.5} \mathrm{O}_{4}$. We found that the nanosized octahedral structure can not only accommodate the lattice stress caused by JohnTeller distortion but also provide short paths for $\mathrm{Li}^{+}$ion transportation in the material. Additionally, the obtained predominant (111) facet is helpful to the formation of protective SEI film on the spinel $\mathrm{LiNi}_{0.5} \mathrm{Mn}_{1.5} \mathrm{O}_{4}$ electrode.

\section{Introduction}

Li-ion batteries (LIBs) have achieved great success in portable electronics and are widely studied for electric vehicles (EVs) and hybrid electric vehicles (HEVs) due to its advantages such as high energy density, long lifespan, environment benignity and no memory effect [1-3]. In order to meet the applications in EVs and HEVs, further improvement of energy density for LIBs is required $[4,5]$. An effective approach for improving the energy density of LIBs is to explore the cathode materials with higher operating potential and large specific capacity [6, 7].

Among the diverse materials that have been studied as potential cathode materials for LIBs, $\mathrm{LiNi}_{0.5} \mathrm{Mn}_{1.5} \mathrm{O}_{4}$ (LNMO) has received attention as a promising candidate for high energy density LIBs because of its high operating voltage ( $4.75 \mathrm{vs}$. $\left.\mathrm{Li} / \mathrm{Li}^{+}\right)$, and high specific capacity $\left(146.7 \mathrm{mAh} \mathrm{g}^{-1}\right)$ as well $[8,9]$. Despite these outstanding features, the practical application of LNMO in LIBs is still restricted by two problems. First, presence of $\mathrm{Mn}^{3+}$ formed during charge/discharge processes leads to the John-Teller distortion causing severe structural instability $[10,11]$. Second, the dissolution of $\mathrm{Mn}$ resulting from the spinel lattice, especially at elevated temperature $[12,13]$. Strategies including cations doping and/or surface coating have been proposed to address the problems as mentioned above [14-16], but these method always accompanied by compromising the theoretical capacity and complicated synthetic process $[17,18]$.

Recently, particle shapes and sizes of electrode materials are known to play a critical role in determining their electrochemical properties $[19,20]$. LNMO with nano-structures shows enhanced electrochemical properties in terms of cyclic stability and rate capability [21, 22]. Nanostructure materials can increase the 
contact between electrode and electrolyte and reduce the path length for the $\mathrm{Li}^{+}$diffusion, resulting in good rate capability. Additionally, nano-structure can buffer the lattice stress caused by John-Teller effect upon cycling and thus improve the cycling stability of LNMO material [23, 24].

It was reported that the crystallographic facets of the LNMO material can affect its electrochemical performance [25]. For example, the (111) facet in the spinel LNMO shows better cycling stability than other facets such as (100) and (110). Previous study reveals that the SEl layer formed on the (111) facet is thinner and smoother compared to the (100) and (110) facets [26]. What is more, the (111) facet can promote the $\mathrm{Li}^{+}$intercalation/deintercalation in the $\mathrm{LNMO}$, resulting in the enhanced rate capability of the LNMO [27]. Therefore, the nano-structure of LNMO with exposed (111) facet could be considered as a promising method to improve the cycling stability and rate capability of the LNMO material.

In this study, we proposed the preparation of nanosized octahedral $\mathrm{LiNi}_{0.5} \mathrm{Mn}_{1.5} \mathrm{O}_{4}$ (O-LNMO) with predominant (111) via a two-step synthesis, which is schematically shown in Fig. 1: we first synthesized the $\mathrm{Mn}_{3} \mathrm{O}_{4}$ nanoparticles precursor by a hydrothermal treatment, and then impregnated the obtained $\mathrm{Mn}_{3} \mathrm{O}_{4}$ precursor with an ethanol solution of $\mathrm{Li}$ and Ni precursors, followed by solvent evaporation and a high temperature solid state reaction. The crystal structure and morphology of the synthesized O-LNMO were characterized by XRD, SEM and TEM. When evaluated as cathode material for LIBs, the as prepared O-LNMO shows excellent electrochemical performance in terms of reversible capacity, cycling stability and rate capability. Based on these results, the as prepared product is a promising cathode candidate for high energy density LIBs, and we conclude that the preparation of O-LNMO from the $\mathrm{Mn}_{3} \mathrm{O}_{4}$ precursor has a beneficial role in the synthesis of LNMO materials. To the best of our knowledge, there is seldom report on the preparation of $\mathrm{LNMO}$ using $\mathrm{Mn}_{3} \mathrm{O}_{4}$ as precursor.

\section{Experimental Section}

\subsection{Materials synthesis}

$\mathrm{Mn}_{3} \mathrm{O}_{4}$ precursor was synthesized by a hydrothermal reaction. Briefly, $1.0 \mathrm{mmol} \mathrm{Mn}\left(\mathrm{CH}_{3} \mathrm{COO}\right)_{2} \bullet 4 \mathrm{H}_{2} \mathrm{O}$ and $8 \mathrm{~mL}$ glycerol were dissolved into a solution mixture of $25 \mathrm{~mL}$ DI water and $25 \mathrm{~mL}$ isopropanol, and the above mixture was stirred for $0.5 \mathrm{~h}$. Then, the formed mixture was transferred into a $100 \mathrm{~mL}$ Teflon-lined stainless steel autoclave, and heated at $180^{\circ} \mathrm{C}$ for $6 \mathrm{~h}$. After the autoclave was cooled naturally to room temperature, the $\mathrm{Mn}_{3} \mathrm{O}_{4}$ products were collected and washed by centrifugation several times with DI water and absolute ethanol before dried in a vacuum oven at $60^{\circ} \mathrm{C}$ overnight

For the preparation of O-LNMO, the obtained $\mathrm{Mn}_{3} \mathrm{O}_{4}$ precursor, stoichiometric amounts of the obtained $\mathrm{Mn}_{3} \mathrm{O}_{4}$ precursor, $\mathrm{Ni}\left(\mathrm{CH}_{3} \mathrm{COO}\right)_{2} \cdot 4 \mathrm{H}_{2} \mathrm{O}$ and $\mathrm{LiCH}_{3} \mathrm{COO} \cdot 2 \mathrm{H}_{2} \mathrm{O}$ ( $\mathrm{Li}$ excessive $5 \%$ ) were well dispersed in $10 \mathrm{~mL}$ ethanol. After ethanol evaporation, the resulting products were calcined at $800{ }^{\circ} \mathrm{C}$ in air for $10 \mathrm{~h}$ to obtain the final O-LNMO 
As a comparison, bulk LNMO (B-LNMO) was also prepared by a sucrose-assist combustion method to illustrate the effect of the prepared O-LNMO. Typically, $2 \mathrm{~g}$ sucrose was added to $30 \mathrm{~mL}$ DI water, $\mathrm{Ni}\left(\mathrm{CH}_{3} \mathrm{COO}\right)_{2} \cdot 4 \mathrm{H}_{2} \mathrm{O}, \mathrm{Mn}\left(\mathrm{CH}_{3} \mathrm{COO}\right)_{2} \cdot 4 \mathrm{H}_{2} \mathrm{O}$ and $\mathrm{LiCH}_{3} \mathrm{COO} \cdot 2 \mathrm{H}_{2} \mathrm{O}$ (Li excessive $5 \%$ ) were added to the above mixture in a molar ratio. Then the resulting solution was heated to $90{ }^{\circ} \mathrm{C}$ under stirring condition to evaporate water. Finally, the obtained precursor was calcined at $800^{\circ} \mathrm{C}$ for $10 \mathrm{~h}$ in air.

\subsection{Materials characterization}

Crystallographic information of the samples was investigated with X-ray diffraction analysis (XRD, Bruker D8 ADVANCE, Germany). The morphology and structures of the samples were examined using scanning electron microscopy (SEM, Merlin, Germany), and transmission electron microscopy (TEM, JEM-2100HR, Japan). After cycling, cells were carefully opened in a glovebox to retrieve the electrodes for SEM observation and ICP analysis. The cycled LNMO electrodes and Li foils extracted from the cells were rinsed with anhydrous DMC to remove residual Li salt and EC, and then followed by drying at room temperature overnight in the antechamber under vacuum. The contents of $\mathrm{Mn}$ and $\mathrm{Ni}$ deposited on $\mathrm{Li}$ foils were determined by ICP-MS (IRIS Intrepid II XSP, USA)

\subsection{Electrochemical measurements}

Electrochemical properties were measured using two-electrode coin cells (CR2025) in an argon-filled glovebox, in which the moisture and oxygen concentration were less than $1.0 \mathrm{ppm}$. The working electrode was fabricated by blending the prepared LNMO samples, acetylene black and polyvinylidene fluoride at a ratio of 8:1:1 in N-methyl-2-2pyrrolidone. The slurry was mixed and coated onto a piece of Al foil followed by drying at $120^{\circ} \mathrm{C}$ for $2 \mathrm{~h}$. Lithium metal was employed as the counter electrode and reference electrode, Celgard 2400 as separator, and the electrolyte was 1.0 M LiPF 6 dissolved in ethylene carbonate/dimethyl carbonate/ethyl methyl carbonate (1/1/1 in volume). A battery test system (LAND, CT2001A, China) was used for charging/discharging tests of the cells. Cyclic voltammetry is conducted on an Arbin testing system (BT2000, USA).

\section{Results And Discussion}

Scanning electron microscopy (SEM) and transmission electron microscopy (TEM) provide insights into the morphology and detail structure of the samples. As shown in Fig. 2a, the as-prepared $\mathrm{Mn}_{3} \mathrm{O}_{4}$ precursor exhibits nanoparticle shape, demonstrating a random particle distribution with a range of diameters of 30 to $60 \mathrm{~nm}$. The structure of the as-prepared $\mathrm{Mn}_{3} \mathrm{O}_{4}$ precursor could further be demonstrated by their TEM image shown in Fig. 2b, where the $\mathrm{Mn}_{3} \mathrm{O}_{4}$ nanoparticles with sizes of $40 \mathrm{~nm}$ could clearly visualized. The relatively darker locations in Fig. $2 b$ appear to indicate the as-prepared $\mathrm{Mn}_{3} \mathrm{O}_{4}$ nanoparticles with slight agglomeration. As is well known, nanoparticles tend to aggregate into large secondary forms owing to their high surface energies and small dimensions. To synthesis the $\mathrm{LNMO}$, the as-prepared $\mathrm{Mn}_{3} \mathrm{O}_{4}$ precursor are immersed in ethanol containing $\mathrm{Ni}\left(\mathrm{CH}_{3} \mathrm{COO}\right)_{2} \bullet 4 \mathrm{H}_{2} \mathrm{O}$ and $\mathrm{LiCH}_{3} \mathrm{COO} \cdot 2 \mathrm{H}_{2} \mathrm{O}$, followed by evaporation. After ethanol evaporation, the resulting products were calcined at $800{ }^{\circ} \mathrm{C}$ in air to obtain O-LNMO, and the formation of O-LNMO is illustrated by Fig. 1. It can be seen 
from Fig. $2 \mathrm{c}$ that the obtained O-LNMO powders show octahedral structure with clean and smooth surface facets, suggesting the O-LNMO are well crystallized, and the particle size ranging from 600 to $800 \mathrm{~nm}$, which is typically different from the $\mathrm{Mn}_{3} \mathrm{O}_{4}$ nanoparticles precursor as discussed above, indicating the octahedral structure is well formed after calcined at high temperature. TEM observation (Fig. 2d) reveals that the LNMO particles display octahedral shapes with well-defined edges and corners, which is in good agreement with SEM examination.

XRD was conducted to identify the crystallographic structure of the prepared samples. As can be seen from Fig. 3a, all the XRD patterns can be indexed to the well-known tetragonal hausmannite crystal structure model of $\mathrm{Mn}_{3} \mathrm{O}_{4}$ (JCPSD no. 24-0734) [28], which is in accordance with the previous reports. No characteristic peaks related to impurities are observed, which suggests the pure $\mathrm{Mn}_{3} \mathrm{O}_{4}$ can be prepared by the hydrothermal process. It can be seen from Fig. 3b that the LNMO displays typical profile of spinel phase (JCPDS no. 80-2162) with Fd3m cubic space group [29]. The as-prepared LNMO shows sharp and strong diffraction peaks, indicating its good crystallinity, which is beneficial to cycling performance and high discharge capacity. As shown, minor residues peaks (as marked asterisks) at $2 \theta=$ $37.52,43.62$ and 63.42 that can be attributed to $\mathrm{Li}_{x} \mathrm{Ni}_{1-\mathrm{x}} \mathrm{O}_{2}$ [21]. This is a common phenomenon that such impurities can be detected in the preparation of $\mathrm{LiNi}_{0.5} \mathrm{Mn}_{1.5} \mathrm{O}_{4}$. To illustrate the effect of the prepared O-LNMO, bulk LNMO (B-LNMO) was also prepared by a sucrose-assist combustion method. As is shown in SFig.1, the B-LNMO exhibits irregular ployhedron shape with multiply facets and severe aggregation after annealing at $800^{\circ} \mathrm{C}$, indicating that it is difficult to control the morphology of the LNMO materials in terms of such method. As a comparison, XRD patterns of O-LNMO and B-LNMO are shown in Fig. 4, all peaks of the two samples can be assigned to the spinel structure with a space group of Fd3m. When all the peaks in the XRD patterns are normalized by the (311) peak, the (111) and (400) peaks of OLNMO are more intensive than that of B-LNMO. The relative peak intensities reflect the dominant surface orientations of the products. This result suggests both the prepared samples have the same spinel structure but different crystallographic facets, which might result in different electrochemical performance.

To study the electrochemical properties of the prepared LNMO, half cells were assembled using Li metal as reference and counter electrodes. The cyclic voltammetry (CV) curves of B-LNMO and O-LNMO were shown in Fig. 5a, for the both samples, there two pairs of redox peaks centered in the high voltage of 4.6 $\sim 4.9 \mathrm{~V}$, relating to the reversible reactions of $\mathrm{Ni}^{3+} / \mathrm{Ni}^{4+}$ and $\mathrm{Ni}^{2+} / \mathrm{Ni}^{3+}$ couples [30], while a pair of broad and weak peak due to the $\mathrm{Mn}^{3+} / \mathrm{Mn}^{4+}$ couple could be also seen around 4.0V [18]. The 0-LNMO sample exhibits slight higher peak current density and more symmetrical redox than the B-LNMO, indicating enhanced electrode reactivity. Figure $5 \mathrm{~b}$ shows the cycling performance of the O-LNMO and B-LNMO, the O-LNMO delivers a discharge capacity of about $117 \mathrm{mAh} \mathrm{g}^{-1}$ after 300 cycles, and maintains $94 \%$ of its initial discharge capacity $\left(124.7 \mathrm{mAh} \mathrm{g}^{-1}\right)$ at $1 \mathrm{C}$, while in the B-LNMO case, the discharge capacity of the cell with B-LNMO electrode decreases from 122.3 to $108 \mathrm{mAh} \mathrm{g}^{-1}$ with a capacity retention of $88 \%$, which suggests the O-LNMO electrode shows better cycling stability. To evaluate the rate capability of the prepared samples, the cells were charged at a rate of $0.5 \mathrm{C}$ and discharged at different rate currents 
ranging from $0.5 \mathrm{C}$ to $40 \mathrm{C}$ between 3.5 and $4.9 \mathrm{~V}$, Fig. $5 \mathrm{c}$ shows the obtained results, both the O-LNMO and B-LNMO electrodes suffer from a substantial decrease with increasing the rate, it is obvious that the O-LNMO has a better rate capacity than the B-LNMO counterpart, even at a rate of $40 \mathrm{C}$, a specific capacity of $99.2 \mathrm{mAh} \mathrm{g}^{-1}$ could be still obtained for the O-LNMO, while is only $26.7 \mathrm{mAh} \mathrm{g}^{-1}$ for the BLNMO. Moreover, O-LNMO exhibits obviously slower capacity decay with increasing discharge rates. These suggest that the O-LNMO shows better rate capacity and cyclability than that of B-LNMO. The remarkable improvement of rate capacity of the O-LNMO can be ascribed to nanosized octahedral $\mathrm{LiNi}_{0.5} \mathrm{Mn}_{1.5} \mathrm{O}_{4}$ with exposed (111) facet, which can facilitate $\mathrm{Li}^{+}$insertion/deinsertion in the LNMO electrode. The long-term cycling performance of the 0-LNMO electrode is shown in Fig. 5d, after cycling at $5 \mathrm{C}$ for 2000 cycles, the O-LNMO can still deliver a discharge capacity of $86.7 \mathrm{mAh} \mathrm{g}^{-1}$ with $73 \%$ capacity retention, meaning only $0.0135 \%$ capacity decay per cycle. The excellent cycling stability and rate capability from the O-LNMO indicates its potential application for the high performance lithium-ion batteries.

Surface morphology of the O-LNMO and B-LNMO electrodes after 300 cycles are observed by SEM. It can be observed from Fig. $6 \mathrm{~b}$ that some of the B-LNMO particles suffered destruction after cycling, which might be attributed to the transition metal dissolution during cycling. On the contrary, the structure of the O-LNMO particles maintained well (Fig. 6a), the octahedral morphology can be identified clearly.

Moreover, the surface of the B-LNMO electrode is covered with nonuniform and thick surface layer, which can be ascribed to the severe decomposition of the electrolyte cycling upon high voltage. Different from the case of B-LNMO, the O-LNMO shows uniform and thin deposit on the surface layer, indicating there is less electrolyte decomposition on the O-LNMO particle, which results from the formation of the stable SEI due to the exposed (111) facet.

To further investigate the effect of the 0-LNMO, the images of the cycled Li anodes was shown in Fig. 7. The smooth and clean surfaces of the Li anodes no longer exist, and significant changes can be seen on both cycled Li anodes. It can be observed that much more slurry precipitated on the Li anode extracted from the cell with B-LNMO cathode than that taken from cell with O-LNMO cathode. Therefore, ICP-MS was used to further analyze the chemical composition of the precipitated slurry on the cycled Li anodes. The two cycled Li anodes were first washed with DMC for several times, and dissolved in $2 \% \mathrm{HNO}_{3}$ solution, followed by adding deionized water to $25 \mathrm{~mL}$. As is shown in Table S1, it can be seen that the content of $\mathrm{Mn}$ and $\mathrm{Ni}$ for the Li anode extracted from the O-LNMO cell are much lower than that with BLNMO cell. The results of ICP-MS experiment suggests that dissolution of $\mathrm{Mn}$ and Ni from the LNMO cathode can be reduced, which might be ascribed to the structural stability and the stable SEl formed on the (111) facet resulting from the nanosized octahedral LNMO.

\section{Conclusions}

In this work, we have synthesized nanosized octahedral $\mathrm{LiNi}_{0.5} \mathrm{Mn}_{1.5} \mathrm{O}_{4}$ with predominant (111) facet using $\mathrm{Mn}_{3} \mathrm{O}_{4}$ nanoparticles precursor. The crystal structure, morphology characteristics, and 
electrochemical performance of the LNMO were thoroughly investigated. The resultant octahedral $\mathrm{LiNi}_{0.5} \mathrm{Mn}_{1.5} \mathrm{O}_{4}$ with nanosized structure can buffer the lattice stress caused by John-Teller distortion and favour fast $\mathrm{Li}^{+}$intercalation kinetics. Moreover, stable and protective SEl formed on the LNMO can be obtained due to the exposed (111) facet. As a result, the LNMO exhibits excellent cyclic stability and rate capability. We think that the results reported here may shed more light on the practical application of LNMO material, which would promote the development of the high energy density LIBs.

\section{Declarations}

\section{Acknowledgments}

This work is financially supported from the Guangdong Basic and Applied Basic Research Foundation (No. 2019A1515110528).

\section{References}

1. Tarascon JM, Armand M (2001) Issues and challenges facing rechargeable lithium batteries. Nature 414:359-367

2. Wang S, Yang Y, Dong Y et al (2019) Recent progress in Ti-based nanocomposite anodes for lithium ion batteries. J Adv Ceram 8:1-18

3. Li W, Song B, Manthiram A et al (2017) High-voltage positive electrode materials for lithium-ion batteries. Chem Soc Rev 46:3006-3059

4. Rong $\mathrm{H}$, Xu M, Xing $\mathrm{L}$ et al (2014) Enhanced cyclability of $\mathrm{LiNi}_{0.5} \mathrm{Mn}_{1.5} \mathrm{O}_{4}$ cathode in carbonate based electrolyte with incorporation of tris(trimethylsilyl)phosphate (TMSP). J Power Sources 261:148-155

5. Xia Y, Zheng J, Wang $\mathrm{C}$ et al (2018) Designing principle for Ni-rich cathode materials with high energy density for practical applications. Nano Energy 49:434-452

6. Rong $\mathrm{H}$, Xie G, Cheng $\mathrm{S}$ et al (2016) Hierarchical porous $\mathrm{ZnMn}_{2} \mathrm{O}_{4}$ microspheres architectured with sub-nanoparticles as a high performance anode for lithium ion batteries. J Alloys Compd 679:231238

7. Zhao X, Liu B, Yang J et al (2020) Synthesizing $\mathrm{LiNi}_{0.5} \mathrm{Co}_{0.2} \mathrm{Mn}_{0.3} \mathrm{O}_{2}$ with microsized peanut-like structure for enhanced electrochemical properties of lithium ion batteries. J Alloys Compd 832:154464

8. Fang X, Shen C, Ge M et al (2015) High-power lithium ion batteries based on flexible and light-weight cathode of $\mathrm{LiNi}_{0.5} \mathrm{Mn}_{1.5} \mathrm{O}_{4} /$ carbon nanotube film. Nano Energy 12:43-51

9. Park JS, Meng X, Elam JW et al (2014) Ultrathin Lithium-lon Conducting Coatings for Increased Interfacial Stability in High Voltage Lithium-Ion Batteries. Chem Mater 26:3128-3134

10. Santhanam R, Rambabu B (2010) Research progress in high voltage spinel $\mathrm{LiNi}_{0.5} \mathrm{Mn}_{1.5} \mathrm{O}_{4}$ material. J Power Sources 195:5442-5451 
11. Rong $\mathrm{H}, \mathrm{Xu} \mathrm{M}, \mathrm{Xie} B$ et al. A novel imidazole-based electrolyte additive for improved electrochemical performance at elevated temperature of high-voltage $\mathrm{LiNi}_{0.5} \mathrm{Mn}_{1.5} \mathrm{O}_{4}$ cathodes. J. Power Sources 32016, 329: 586-593

12. Hanf $\mathrm{L}$, Henschel J, Diehl $\mathrm{M}$ et al (2020) $\mathrm{Mn}^{2+}$ or $\mathrm{Mn}^{3+}$ ? Investigating transition metal dissolution of manganese species in lithium ion battery electrolytes by capillary electrophoresis. Electrophoresis 41:697-704

13. Yin C, Zhou H, Yang Z et al (2018) Synthesis and Electrochemical Properties of $\mathrm{LiNi}_{0.5} \mathrm{Mn}_{1.5} \mathrm{O}_{4}$ for LiIon Batteries by the Metal-Organic Framework Method. ACS Appl Mater Inter 10:13625-13634

14. Guo J, Li Y, Chen Y et al (2019) Stable interface $\mathrm{CO}_{3} \mathrm{O}_{4}$-coated $\mathrm{LiNi}_{0.5} \mathrm{Mn}_{1.5} \mathrm{O}_{4}$ for lithium-ion batteries. J Alloys Compd 811:152031

15. Wei L, Tao J, Yang Y et al (2020) Surface sulfidization of spinel $\mathrm{LiNi}_{0.5} \mathrm{Mn}_{1.5} \mathrm{O}_{4}$ cathode material for enhanced electrochemical performance in lithium-ion batteries. Chem Eng J 384:123268

16. Li F, Ma J, Lin J et al (2020) Exploring the origin of electrochemical performance of Cr-doped $\mathrm{LiNi}_{0.5} \mathrm{Mn}_{1.5} \mathrm{O}_{4}$. Phys Chem Chem Phys 22:3831-3838

17. Xu M, Liu Y, Li B et al (2012) Tris (pentafluorophenyl) phosphine: An electrolyte additive for high voltage Li-ion batteries. Electrochem Commun 18:123-126

18. Rong $\mathrm{H}, \mathrm{Xu} M, \mathrm{Xie} B$ et al (2014) Tris (trimethylsilyl) borate (TMSB) as a cathode surface film forming additive for $5 \mathrm{~V} \mathrm{Li} / \mathrm{LiNi}_{0.5} \mathrm{Mn}_{1.5} \mathrm{O}_{4}$ Li-ion cells. Electrochim Acta 147:31-39

19. Mahmood N, Tang T, Hou Y et al (2016) Nanostructured Anode Materials for Lithium lon Batteries: Progress, Challenge and Perspective. Adv Energy Mater 6:1600374

20. Zhang Q, Uchaker E, Candelaria SL et al (2013) Nanomaterials for energy conversion and storage. Chem Soc Rev 42:3127-3171

21. Zhou L, Zhao D, Lou X et al (2012) $\mathrm{LiNi}_{0.5} \mathrm{Mn}_{1.5} \mathrm{O}_{4}$ hollow structures as high-performance cathodes for lithium-ion batteries. Angew Chem 51:239-241

22. Zhu C, Akiyama T (2014) Designed synthesis of $\mathrm{LiNi}_{0.5} \mathrm{Mn}_{1.5} \mathrm{O}_{4}$ hollow microspheres with superior electrochemical properties as high-voltage cathode materials for lithium-ion batteries. RSC Adv 4:10151

23. Lin HB, Zhang YM, Hu JN et al (2014) $\mathrm{LiNi}_{0.5} \mathrm{Mn}_{1.5} \mathrm{O}_{4}$ nanoparticles: Synthesis with synergistic effect of polyvinylpyrrolidone and ethylene glycol and performance as cathode of lithium ion battery. $J$ Power Sources 257:37-44

24. Cho HM, Chen MV, MacRae AC et al (2015) Effect of Surface Modification on Nano-Structured $\mathrm{LiNi}_{0.5} \mathrm{Mn}_{1.5} \mathrm{O}_{4}$ Spinel Materials. ACS Appl Mater Inter 7:16231-16239

25. Chen Z, Qiu S, Cao Y et al (2012) Surface-oriented and nanoflake-stacked $\mathrm{LiNi}_{0.5} \mathrm{Mn}_{1.5} \mathrm{O}_{4}$ spinel for high-rate and long-cycle-life lithium ion batteries. J Mater Chem 22:17768

26. Hai B, Shukla AK, Duncan $\mathrm{H}$ et al (2013) The effect of particle surface facets on the kinetic properties of $\mathrm{LiMn}_{1.5} \mathrm{Ni}_{0.5} \mathrm{O}_{4}$ cathode materials. J Mater Chem A 1:759-769 
27. Lin HB, Zhang YM, Rong HB et al (2014) Crystallographic facet- and size-controllable synthesis of spinel $\mathrm{LiNi}_{0.5} \mathrm{Mn}_{1.5} \mathrm{O}_{4}$ with excellent cyclic stability as cathode of high voltage lithium ion battery. $\mathrm{J}$ Mater Chem A 2:11987

28. Jiang J, Du K, Cao Y et al (2013) Syntheses of spherical $\mathrm{LiMn}_{2} \mathrm{O}_{4}$ with $\mathrm{Mn}_{3} \mathrm{O}_{4}$ and its electrochemistry performance. J Alloys Compd 577:138-142

29. Yang S, Chen J, Liu Y et al (2014) Preparing $\mathrm{LiNi}_{0.5} \mathrm{Mn}_{1.5} \mathrm{O}_{4}$ nanoplates with superior properties in lithium-ion batteries using bimetal-organic coordination-polymers as precursors. J Mater Chem $\mathrm{A}$ 2:9322-9330

30. Yi TF, Han X, Chen B et al (2017) Porous sphere-like $\mathrm{LiNi}_{0.5} \mathrm{Mn}_{1.5} \mathrm{O}_{4}-\mathrm{CeO}_{2}$ composite with high cycling stability as cathode material for lithium-ion battery. J Alloys Compd 703:103-113

\section{Figures}




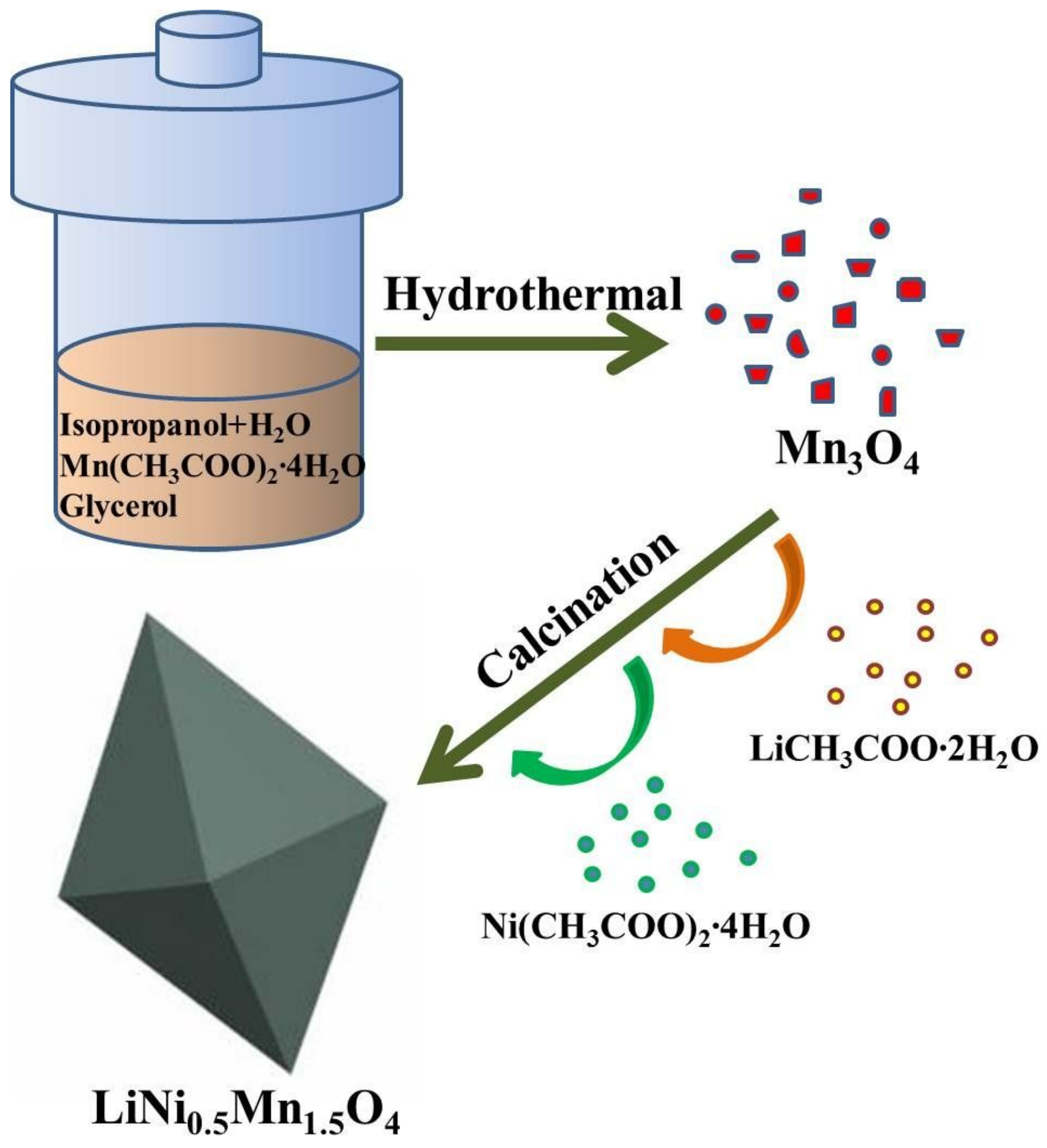

Figure 1

Schematic illustration of the fabrication procedure for the nanosized octahedral LiNi0.5Mn1.504 


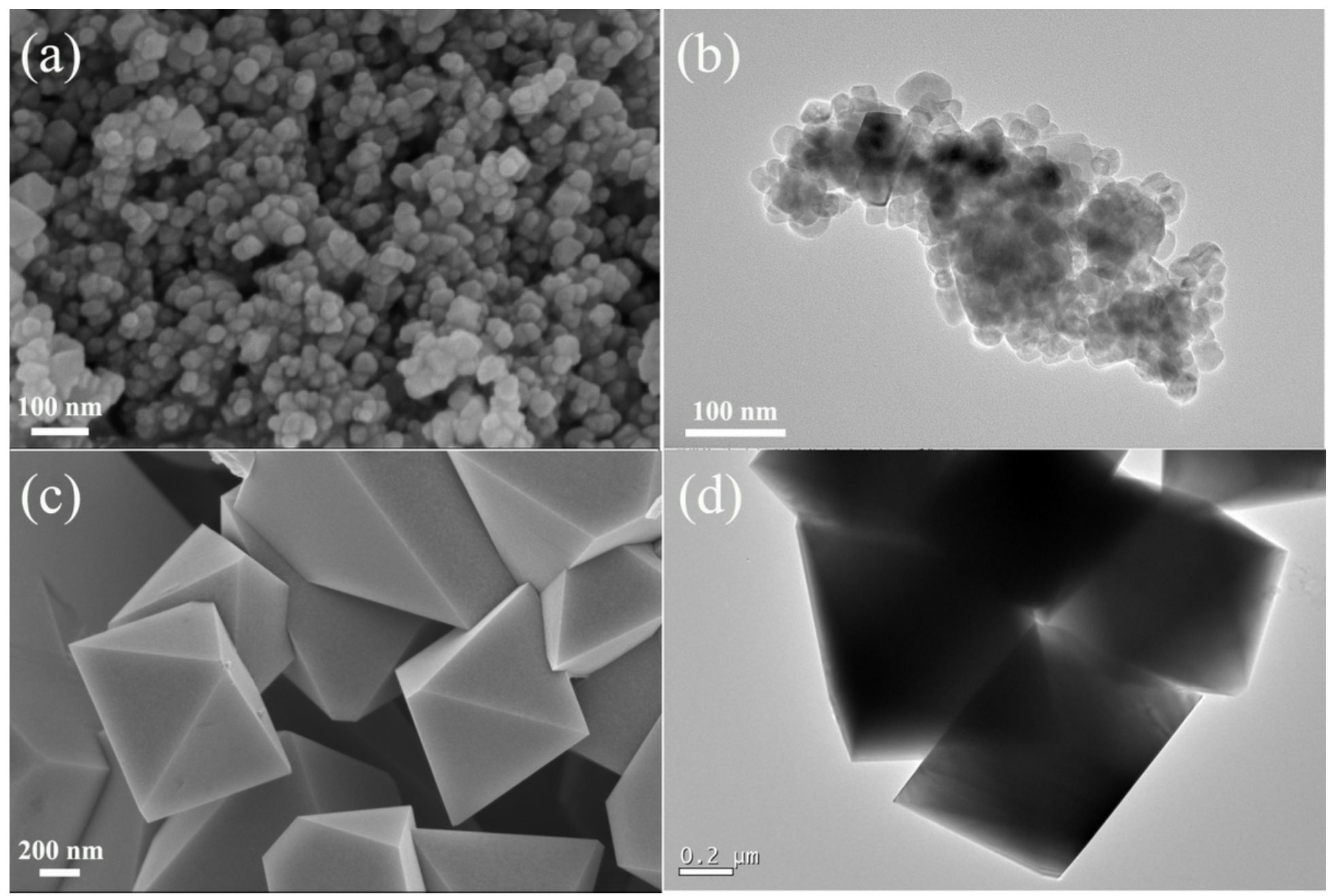

Figure 2

(a) SEM image of the Mn304 precursor, (b) TEM image of the Mn304 precursor, (c) SEM image of the OLNMO, (d) TEM image of the O-LNMO
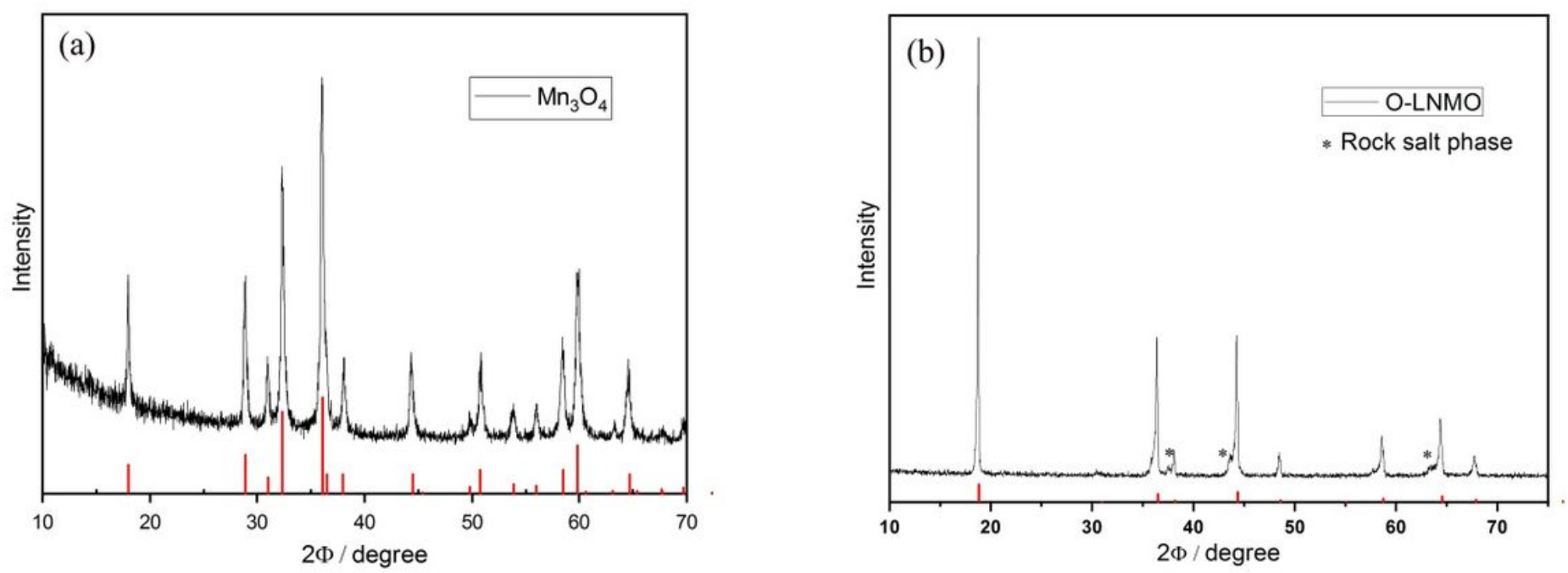

Figure 3 
(a) XRD pattern of the Mn304 precursor, (b) XRD pattern of O-LNMO

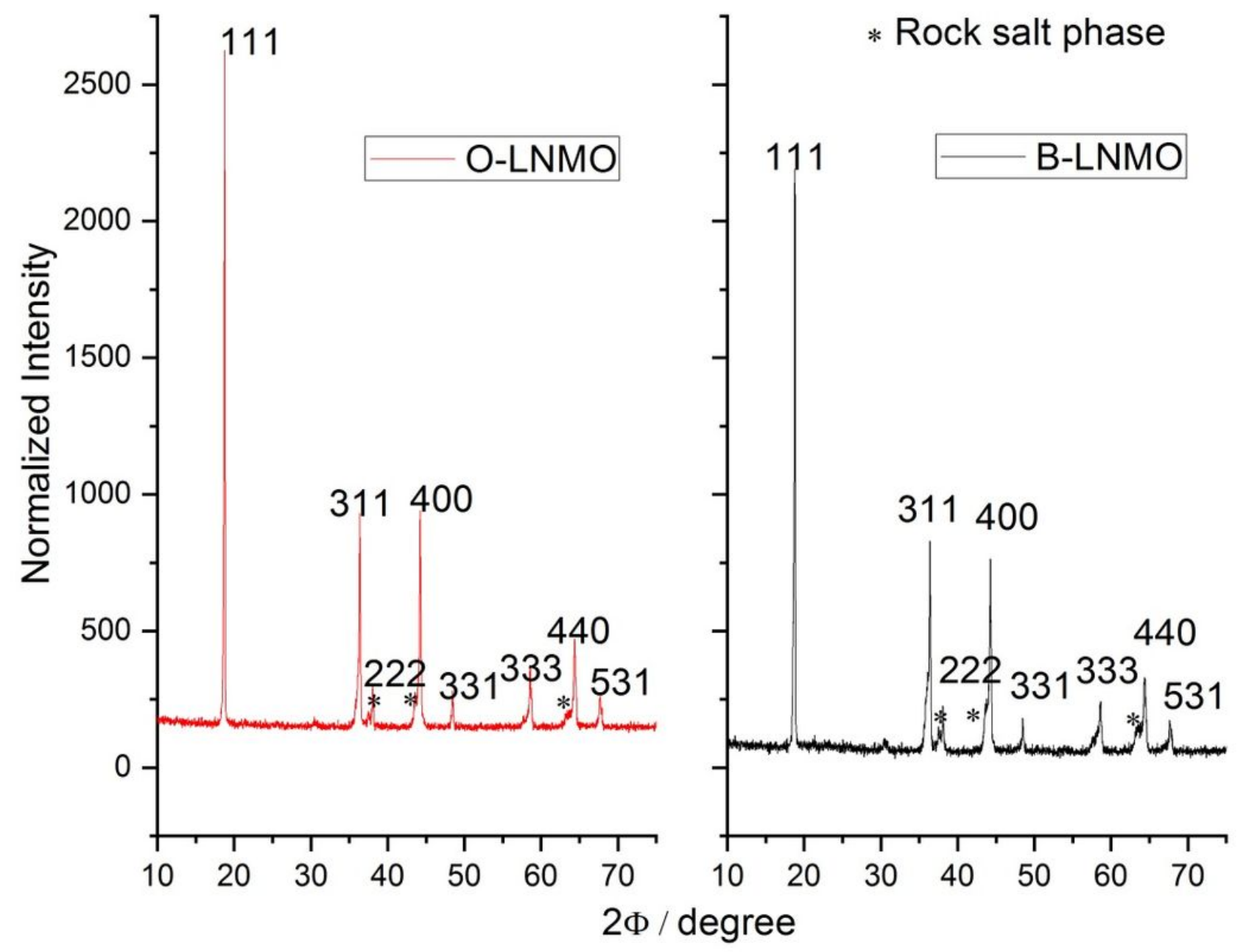

Figure 4

XRD patterns of O-LNMO and B-LNMO normalized by (311) peak 

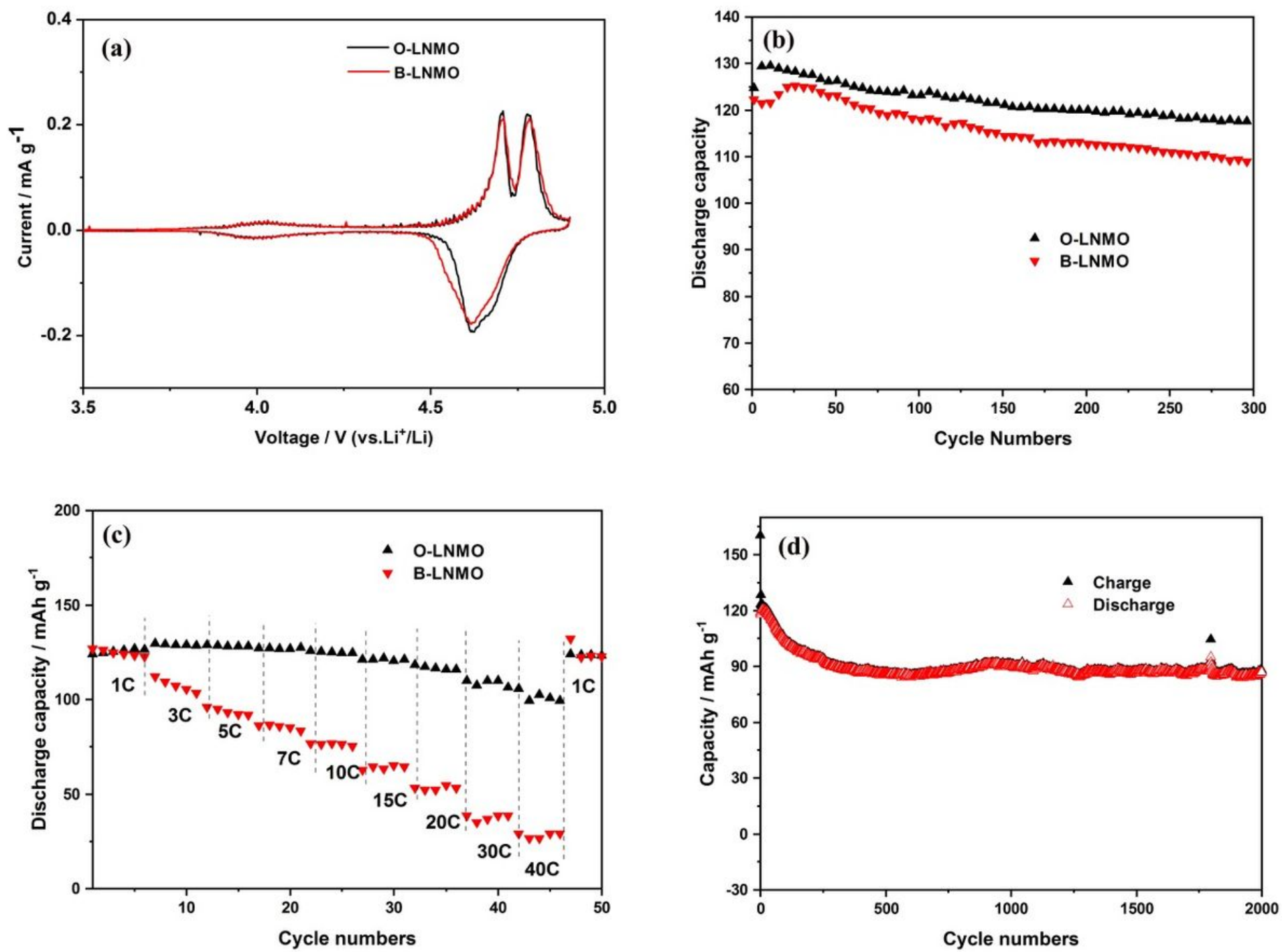

Figure 5

(a) CVs of the O-LNMO and B-LNMO products assembled in coin cell with Li metal as the reference electrode and counter electrode at a scan rate of $0.2 \mathrm{mV} \mathrm{s}-1$ in the voltage range of 3.5-4.9V, (b) Cycling performances of the O-LNMO and B-LNMO at $1 \mathrm{C}$ in the voltage window of 3.5-4.9V, (c) Rate performances of O-LNMO and B-LNMO at various discharge current densities, (d) Long-term cycling performance of $\mathrm{O}-\mathrm{LNMO}$ at $5 \mathrm{C}$ in the voltage range of $3.5-4.9 \mathrm{~V}$ 


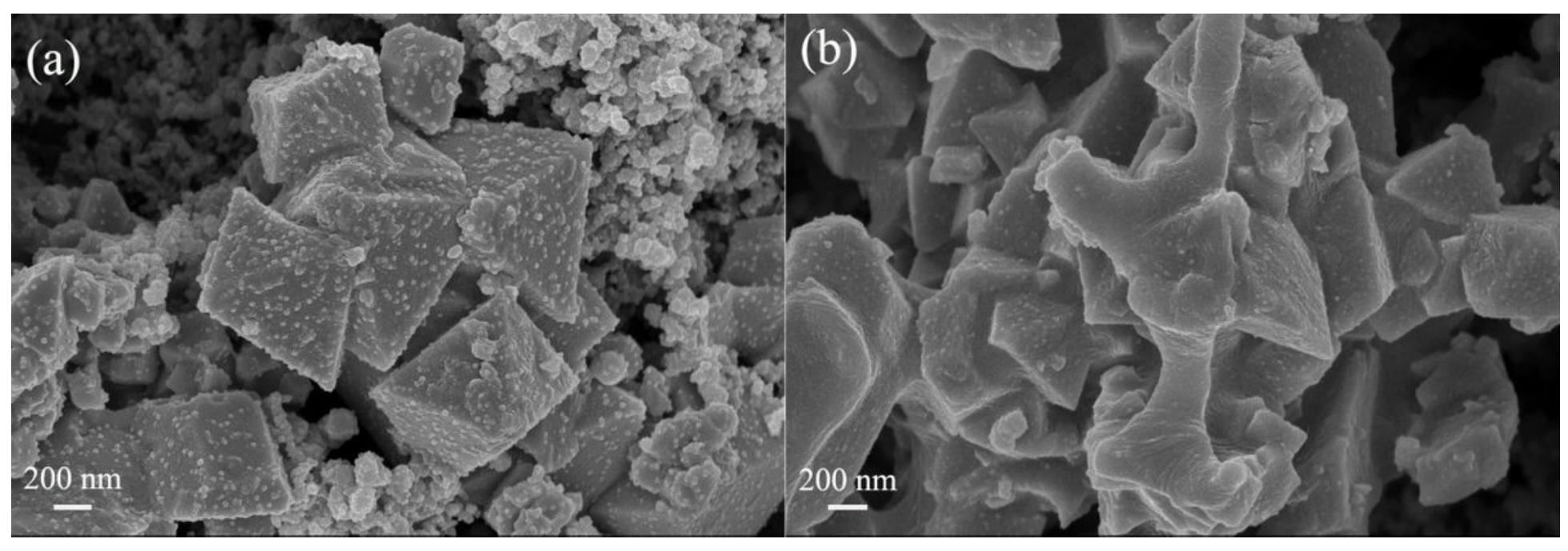

\section{Figure 6}

SEM image of the cycled (a) O-LNMO and (b) B-LNMO electrode, respectively. 
(a)

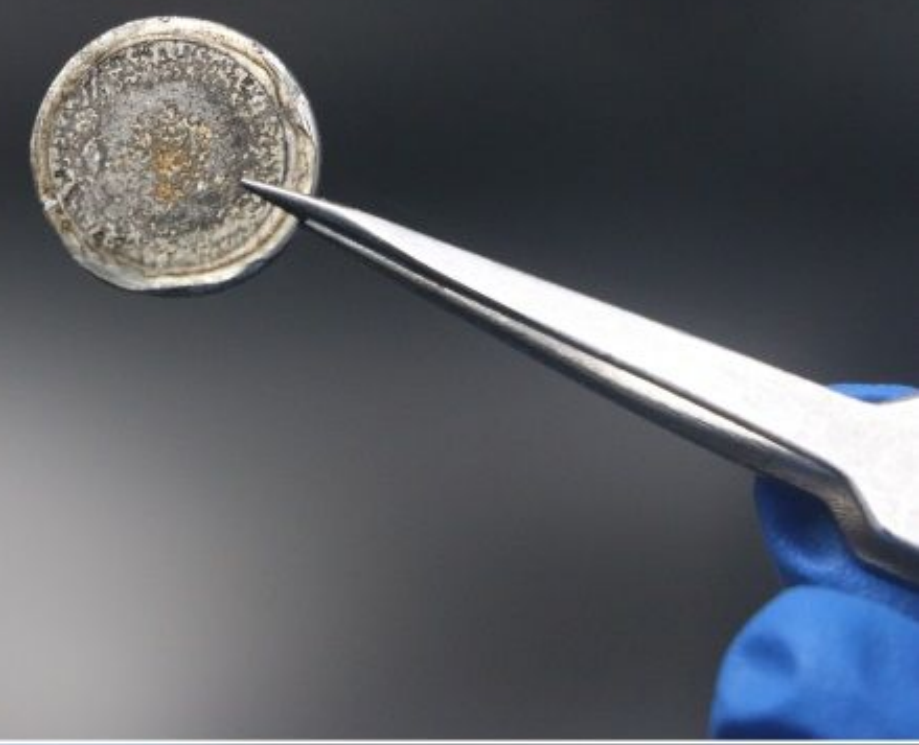

(b)

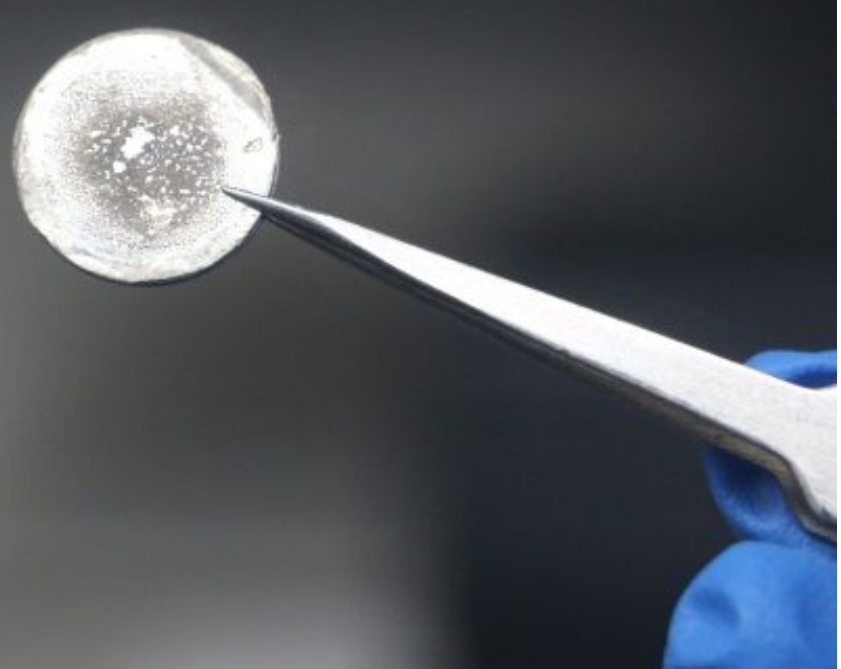

Figure 7

image of the cycled lithium electrodes extracted from the cells with (a) O-LNMO and (b) B-LNMO cathodes, respectively.

\section{Supplementary Files}


This is a list of supplementary files associated with this preprint. Click to download.

- Supplementarydata.docx 